\title{
Updating Labelling Theory: Normalizing but not Enabling
}

\section{Professor Emeritus Thomas Scheff}

Department of Sociology

University of California, Santa Barbara

Email: scheftj@cox.net

\begin{abstract}
In modern societies we often make judgements of certain kinds of behaviour that are virtually automatic: delusions show that one is crazy, wrong answers show that one is ignorant, and so on. The theory of labelling/normalization suggests caution in making these judgements because of the effect they are likely to have on the social relationship, feelings of rejection and embarrassment. There is a social-emotional component in all human contact that can be managed independently of the content. Equal care is needed to avoid both labelling and enabling. Two extended and three brief concrete examples of normalizing are discussed. The social-emotional component seems to be critical in most relationships, both in psychotherapy and education, as suggested by the examples.
\end{abstract}

Keywords: Labelling theory, normalization, psychotherapy, education, symbolic interactionism

\section{Introduction}

This essay begins with the labelling theory of mental illness (Scheff, 1999 [1966]) because it came first. It was accepted by most sociologists, but had little impact in other disciplines and even less on the public at large. It sought to challenge the medical model of what is called mental illness with a social model. In this model, symptoms of mental illness are recast as violations of residual rules: social norms so taken for granted that they go without saying. Most social rules, perhaps, are largely invisible.

For example, in modern societies at least, when one is conversing, one's gaze should be on the other's eyes, rather than forehead or ear. Yet asking anyone to explain the rules of conversation is impracticable; this idea is so taken for granted as to be unthinkable. After all the rules in awareness are named, there is still a universe of other rules that are taken for granted, a huge residue of unconscious rules. This is the territory that Erving Goffman explored in Behavior in Public Places (1964) and in many of his other studies as well.

To find one's ear or forehead the subject of attention might be upsetting. We would be apt to think that the person is not merely rude, but in another world than ours. In our society we call that world insanity, but there may be a better approach. In modern societies, those who are thought to be depressed or 
deluded are usually drugged with little consideration of the details of their particular case. The average dispenser of psychotropic drugs has little incentive to sift through the details. (For a film that makes this point extravagantly, see Numb). Drugging often carries with it labelling and rejection in the sense that such a person is not one of us. Rejection may not be obvious and outright, but subtle in varying degrees.

Labelling theory suggests that in some cases a better way might be normalizing those who break the residual (unstated) rules, rather than labelling, ridiculing or rejecting them. This is not to say that one should always normalize. Automatic responses, whether labelling or normalizing, are equally undesirable. Labelling/normalization theory suggests that we need to decrease automatic responses of both kinds. Automatic normalizing can result in enabling, and automatic labelling can result in social rejection.

The main effect of labelling of any kind is implied by Goffman's treatment of what he called facework, saving and losing face. When one is labelled, one loses face and gains embarrassment, shame, or humiliation. There is a socialemotional element in all human contact. This point is made more directly in Fuller's study (2003) of somebody and nobody feelings. We feel like a somebody when we are accepted, and like a nobody when we are not. What is the percentage of time in 12 or 16 years of school do students feel like nobodies? What does a high percentage of nobody feelings do to students and to our society?

Feeling like a nobody can obviously result from flagrant rejection. However, it can also occur when rejection is subtle. This is a difficult point to make because feeling accepted (connected) is not only hard to achieve in real life, but it is even difficult to describe. There are many terms that are used to describe this state: attunement, shared or mutual awareness, and so on. We take it for granted because we do it, or at least try to do it, for our entire lives. As indicated above, labelling theory has had little impact in the real world. Perhaps one of the problems was that the opposite of labelling, normalizing, was not spelled out concretely enough to be understandable. Many examples of labelling were provided, but few of normalizing. Below are some concrete examples in mental illness and in education. One of the examples is fictional, a film, the other four factual, to try to remedy my earlier omissions.

\section{Normalizing in a Film and in Real Life}

The film, Lars and the Real Girl (Kimmel \& Gillespie 2007), although a comedy, also teaches a powerful lesson: how a community might manage mental illness without the social side effects ('It takes a village...'). The crucial moments occur early in the film. Because Lars has been treating a life-size doll as a real person, his brother, Gus, and sister-in-law, Karin, bring him to their family doctor.

Early in the session, the Doctor asks:

Has Lars been functional? Does he go to work, wash, dress himself?

Gus: $\quad$ So far.

Doctor: Has he had any violent episodes?

Karin: $\quad$ Oh no, no never. He's a sweetheart-he never even raises his voice. 
This dialogue establishes limits the film sets to normalizing: able to take care of self, unlikely to harm self or others. However, there are many other limits that must be set in order to avoid enabling. For example, does he take drugs? In the educational context, to be discussed below, the teacher must take care to accept the student without confirming their mistakes.

Gus: $\quad$ Okay, we got to fix him. Can you fix him?

Dr. Dagmar: I don't know, Gus. I don't believe he's psychotic or schizophrenic. I don't think this is caused by genes or faulty wiring in the brain.

(Preliminary normalizing statement, rejecting diagnosis)

Gus: So then what the hell is going on then?

Doctor: He appears to have a delusion.

Gus: A delusion? What the hell is he doing with a delusion for Christ's sake?

(Gus's manner implies that Lars's behaviour is abnormal)

Doctor: You know, this isn't necessarily a bad thing. What we call mental illness isn't always just an illness. It can be a communication, it can be a way to work something out.

(This is the doctor's central normalizing statement: Lars is not abnormal, he is just communicating.)

Gus: $\quad$ Fantastic, when will it be over?

Doctor: When he doesn't need it anymore.

In this fable, Lars has been scripted to find an extraordinarily unconventional doctor. Not prescribing psychiatric drugs for symptomatic patients now amounts to heresy, or at least is not acceptable practice. I have a psychiatrist friend (I shall call her Dr. D) who is a real-life Dr. Dagmar. She left her first and only full-time job under pressure because she normalized rather than prescribed psychiatric drugs.

For example, Dr. D treated a young man who was unable to keep still, complained of restlessness, fidgeted, rocked from foot to foot, and paced. She told him and his employer that he was not mentally ill, but drugged by the antidepressant he was taking (Prozac), which proved to be correct. Lest this instance seem too obvious, I know of many similar cases where the presiding physician decided that the problem was not too much drug, but too little. A vast difference of outlook separates the great majority of labelling physicians from the few normalizing ones.

Dr. D has had nothing but trouble from the establishment because of her normalizing approach. Seven years after leaving her full-time job, she has been unable to find a regular position as a psychiatrist, even though she is recognized as an authority in her psychiatric specialty.

A much more likely response to Lars in real life would have been for the doctor to say, 'OK. Let's start him on an anti-psychotic medication, since we don't want his symptoms to get worse.' If Karin had said, 'But what about side 
effects? Aren't they sometimes more dangerous than the illness?' The doctor would have replied, 'Karin, I'm sure you realize that he could become much more ill, or even violent.'

For drama and comedy, the film enlists the whole community to help Lars. But in real life, perhaps fewer people would be needed; even one person might be enough. Jay Neugeboren (1999) has investigated many cases in which there was great improvement or complete recovery from what had been diagnosed as 'serious mental illness'. The common thread he has found was that at least one person treated the afflicted one with respect, sticking by him or her through thick or thin. ${ }^{1}$

Until recently, I had not realized that in the actual dialogue, in order to normalize suspect behaviour, the healer must specifically translate the discourse out of the labelling mode into the normalizing mode, and be prepared to accept the consequences from the world of automatic labelling. In the fictional case, the doctor said, in effect, you are not mentally ill, you are just communicating. In the real case, the psychiatrist said, you are not mentally ill, you are just drugged.

\section{Inadvertent Normalizing}

Ironically, because I didn't understand the actual look of normalization, I didn't recognize it occurring in my own next study. At the time that my book was being first published (1966), I observed a series of very brief recoveries from depression. As a visiting researcher at Shenley Hospital (UK) in 1965, I was present for all intake interviews of male patients for six months: 83 patients in all. Of this number 70 patients were 60 or older.

The comments that follow concern the older men. Every one of them was presented as deeply depressed in their speech and manner. However, to my surprise, there were moments in some of the interviews that seemed to be miracles of recovery. It took many years for me to understand what I had observed in terms of labelling theory.

Many of the patients were virtually silent, or gave one-word answers. Long before I came, some of the interviewing psychiatrists had found a way of getting more responses to their questions. In the interviews I observed, 41 of the patients were asked about their activity during World War II. For 20 of those asked this question, the responses shocked me. As they began to describe their activities during the war, their behaviour and appearance underwent a transformation.

Those who changed in the greatest degree sat up, raised their voice to a normal level instead of whispering, held their head up, and looked directly at the psychiatrist, usually for the first time in the interview. The speed of their speech picked up, often to a normal rate, and became clear and coherent, virtually free of long pauses. Their facial expression became lively and showed more colour. Each of them seemed like a different, younger, person.

\footnotetext{
1 The biography (Nasar, 1998) of John Nash, a Nobel Prize winner, is similar. Although Nash is not included in Neugeboren's book, the biography shows that Nash's mother and wife aided his recovery, since they never gave up on him.

However, A Beautiful Mind, a film purportedly based on Nash's biography, is misleading on the drug issue. Nash, played by Russell Crowe, attributes his complete recovery to 'the newer antipsychotic drugs'. But the biography states that Nash refused to take drugs after 1970, long before the newer antipsychotics. Indeed, the biographer states that his refusal may have been fortunate, making possible his complete recovery (Nasar, 1998, p. 353).
} 
The majority changed to a lesser extent, but in the same direction. I witnessed 20 awakenings, some very pronounced, however temporary. The psychiatrists told me that they had seen it happen many times. After witnessing the phenomenon many times, I, like the psychiatrists, also lost interest.

Many years later, because of my work on shame, I proposed a partial explanation (2001): depression involves the complete repression of painful emotions (such as shame, grief, fear, and anger), and lack of a single secure bond. The memory of the patients' earlier acceptance as valued members of a nation at war relived the feeling of acceptance. This feeling generated pride that counteracted the shame part of their depression.

Telling the psychiatrist about belonging to a community during WWII had been enough to remove the shame of being outcasts. Conveying to the psychiatrist that 'once, we were kings' had momentarily relieved their shame and therefore their depressive mood.

When the psychiatrists asked the depressed outcast men about their experience during WWII, they were inadvertently normalizing the patients, returning them, for just a few moments, to what it felt like to be an accepted member of society, rather than labelled and rejected. My recent article on depression (2009) explained some of the implications for social, rather than medical, treatment of mental illness.

However, because I had not used enough concrete instances in my theory, I still had not recognized the way the psychiatrists' question could be interpreted in terms of labelling theory. The psychiatrists' intentions were to continue to label the patients: 'You are mentally ill, so I need more information to assist me with your diagnosis.' However, 20 of the patients understood the meaning as normalizing: 'You are socially acceptable now if you were ever accepted even once as a valuable member of a community.' Perhaps a longterm therapy based on this and other social ideas might do better than just temporary recoveries.

\section{Two Examples from Other Fields}

A psychotherapist who was in bereavement and in end-of-life care told me this story. The first time she met a new patient with dementia from brain cancer, the patient said to her: 'O, my! What have you done to your hair?' At this point a relative might have argued: 'Oh Mom, I'm not Jenny, I'm Victoria.' The therapist, instead of arguing, made a gesture of absent-mindedly straightening her hair with her hand, saying: 'I haven't been able to do a thing with it!' They both laughed, and proceeded to have a lively session, punctuated with laughing and crying. (For an argument that catharsis lives, see Scheff, 2007.)

The final example comes from the field of education. My colleague at the University of California, Santa Barbara, also teaches mathematics in an elementary school for underprivileged children. He explains his method:

\footnotetext{
I ask students leading questions about mathematical situations in order to help them discover, understand, and become proficient in mathematics. The basic principle is that when asked to explain a wrong answer, students will discover their mistakes, and by working together as a group, develop their understanding.
}

A key aspect is not quite described; the teacher usually tries to save students from the automatic embarrassment of a wrong answer. One question: How 
many sides does this milk carton have? He is prepared to normalize many of the different answers by having thought ahead: your answer is about the visible side, outside, flat, and so on. His method seeks to avoid automatic judgements: students are not always wrong, just as teachers are not always right. More importantly, in the long run, social acceptance, rather than automatic rejection, might improve our schools and our society. Teachers can learn to give corrective responses without putting the students down: normalizing without enabling.

I have an example from my own student days. As a senior in physics, I had one professor whom I particularly respected, and I thought that he respected me as well. However, one day when I went to the blackboard prepared to grind out the answer to the problem he had given me, I thought of an intuitive answer that was correct. My professor was so astounded that he said, 'Did Jim (the star student) tell you that?' That was the beginning of the end of my love affair with physics: he had labelled me as a plodder, and embarrassed me in front of the class.

\section{Conclusion}

This essay has suggested an idea that might help us individually be better therapists or teachers, and in the long run, change our medical, psychotherapeutic, and educational institutions. The theory of labelling/normalizing alerts us to the dangers of automatic reactions of labelling as well as enabling, and it gives us examples of how both extremes might be avoided. These ideas might help both individuals and societies to grow and to prosper.

\section{Acknowledgements}

This essay has greatly benefitted from comments on an earlier draft by Robert Fuller and Suzanne Retzinger.

\section{References}

Fuller, R. W. (2003) Somebodies and Nobodies. Gabriola Island, BC: New Society.

Goffman, E. (1964). Behavior in Public Places. New York: Free Press.

Kimmel, S. (Producer), \& Gillespie C. (Director) (2007). Lars and the Real Girl [Motion picture]. United States: MGM.

Nasar, S. (1998). A Beautiful Mind. New York: Simon \& Schuster.

Neugeboren, J. (1999). Transforming Madness. New York: William Morrow.

Scheff, T. (1999). Being Mentally III (3rd ed.). Hawthorne, New York: Aldine Transaction.

(2001). Social Components in Depression. Psychiatry. 64(3), 212-224. 
(2007). Catharsis and Other Heresies. Journal of Social, Evolutionary and Cultural Psychology. 1(3), 98-113.

- (2009). A Social Theory and Treatment of Depression. Journal of Ethical and Human Psychiatry, 11(1), 37-49. 